\title{
The Importance of the KR-Rich Region of the Coat Protein of Ourmia melon virus for Host Specificity, Tissue Tropism, and Interference With Antiviral Defense
}

\author{
Marika Rossi,, ${ }^{1}$ Marta Vallino,, ${ }^{1}$ Simona Abbà, ${ }^{1}$ Marina Ciuffo, ${ }^{1}$ Raffaella Balestrini, ${ }^{1}$ Andrea Genre,${ }^{2}$ and \\ Massimo Turina ${ }^{1}$ \\ ${ }^{1}$ Istituto per la Protezione Sostenibile delle Piante, CNR-Torino, Italy; ${ }^{2}$ Dipartimento di Scienze della vita e Biologia dei \\ Sistemi, Università di Torino-Torino, Italy
}

Submitted 8 July 2014. Accepted 17 September 2014.

\begin{abstract}
The N-terminal region of the Ourmia melon virus (OuMV) coat protein (CP) contains a short lysine/arginine-rich (KR) region. By alanine scanning mutagenesis, we showed that the KR region influences pathogenicity and virulence of OuMV without altering viral particle assembly. A mutant, called OuMV $\mathrm{V}_{610}$, with three basic residue substitutions in the KR region, was impaired in the ability to maintain the initial systemic infection in Nicotiana benthamiana and to infect both cucumber and melon plants systemically. The integrity of this protein region was also crucial for encapsidation of viral genomic RNA; in fact, certain mutations within the KR region partially compromised the RNA encapsidation efficiency of the CP. In Arabidopsis thaliana Col-0, OuMV ${ }_{6710}$ was impaired in particle accumulation; however, this phenotype was abolished in $d c l 2 / d c l 4$ and dcl2/dcl3/dcl4 Arabidopsis mutants defective for antiviral silencing. Moreover, in contrast to $\mathrm{CP}_{\mathrm{wt}}$, in situ immunolocalization experiments indicated that $\mathbf{C P} \mathbf{P}_{6710}$ accumulates efficiently in the spongy mesophyll tissue of infected $N$. benthamiana and $A$. thaliana leaves but only occasionally infects palisade tissues. These results provided strong evidence of a crucial role for OuMV CP during viral infection and highlighted the relevance of the $K R$ region in determining tissue tropism, host range, pathogenicity, and RNA affinity, which may be all correlated with a possible CP silencing-suppression activity.
\end{abstract}

Ourmia melon virus (OuMV) is the best-characterized species of the Ourmiaviridae family, which also consists of Epirus cherry virus (EpCV) and Cassava virus $C$ (CaVC) species (King et al. 2012). Three plus-strand RNA molecules form the OuMV genome and each segment encodes a single protein: RNA1 directs synthesis of an RNA-dependent RNA polymerase (RdRp), RNA2 encodes a movement protein (MP), and RNA3 specifies the 22-kDa coat protein (CP) (Rastgou et al. 2009). Ourmiaviruses have affinities with other postive single stranded RNA multipartite viruses, such as the members of the family Bromoviridae, but their unique structural and molecular features have resulted in their classification in a novel viral

Corresponding author: M. Turina; E-mail: m.turina@ivv.cnr.it

* The $\boldsymbol{e}$-Xtra logo stands for "electronic extra" and indicates that one supplementary figure is published online.

(C) 2015 The American Phytopathological Society family. In fact, phylogenetic analyses showed that the members of the family likely went through a very unusual evolutionary process based on a possible reassortment between a plant virus and a mycovirus. In particular, OuMV RdRp shares distant similarity only with RdRp of narnaviruses, a group of viruses which mainly infects fungi; however, the MP is distantly related to MP of plant tombusviruses. The $\mathrm{CP}$ has limited but significant similarity with $\mathrm{CP}$ of plant and mammalian viruses, although its phylogenetic origin remains uncertain (Rastgou et al. 2009). Another peculiarity of the OuMV CP is the unique morphology of the virions among plant viruses: bacilliform particles of three different lengths with pointed ends (Lisa et al. 1988). Ectopic expression of RNA3 in Nicotiana benthamiana does not result in virion formation because the active replication of OuMV is necessary for virus particle assembly (Crivelli et al. 2011). The OuMV CP is strictly dispensable for cell-to-cell and long-distance movement in N. benthamiana; nevertheless, it is crucial for efficient virus spread and high accumulation in upper noninoculated leaves. In fact, without the CP, RNA1 and RNA2 move only rarely from inoculated leaves through the phloem and reach the upper noninoculated leaves, and the infection foci emanating from phloem exit sites on upper leaves are very limited (Crivelli et al. 2011). In $N$. benthamiana agroinfiltrated leaves, green fluorescent protein (GFP)-CP localized in the nucleus and preferentially in the nucleoli of epidermal cells (Crivelli et al. 2011). Such intracellular targeting seems to be determined by a short stretch of amino acids at the $\mathrm{N}$-terminal region of the protein. This region is rich in lysine and arginine residues and mutations of only three amino acids within this region resulted in the complete exclusion of the GFP-CP mutant from the nucleolus (Rossi et al. 2014). These results provide a model whereby the OuMV $\mathrm{CP}$ has a functional activity in addition to its structural role. Therefore, we have investigated the biological significance of the $\mathrm{CP} \mathrm{N}$-terminal region and how mutations within the lysine/ arginine-rich (KR) region affect OuMV pathogenicity and virulence, and suggest a possible role of OuMV CP in contrasting plant antiviral defenses.

\section{RESULTS}

Effects of mutations in the KR region on infectivity and virion formation in $N$. benthamiana plants.

In a previous work, we used several deletion and alaninescanning mutants of the $\mathrm{N}$-terminal KR region $\left({ }_{6} \mathrm{KRKNRRNE}\right.$ $\mathrm{KKK}_{16}$ ) of the $\mathrm{CP}$ to identify the minimal amino acid signal necessary and sufficient to drive the protein to the nucleolus of 
N. benthamiana cells (Rossi et al. 2014). In the present work, we used some of the most significant $\mathrm{CP}$ mutants from that study (Fig. 1) to investigate the relevance of the KR region in the context of viral infection in $N$. benthamiana plants and, in particular, for the ability of OuMV to develop systemic infections and to form viral particles.

All mutants we analyzed were able to systemically infect $N$. benthamiana plants except for the $\Delta(5-16)$ deletion mutant, which lacks the entire KR region. The absence of 12 amino acids of the $\mathrm{KR}$ region resulted in impaired virus pathogenicity, likely because the deletion prevented particle assembly, as observed by transmission electron microscopy (not shown). All other mutants were able to form virus particles that are morphologically similar to wild-type (WT) virions, with the exception of mutant $\Delta(5-11)$, which produced irregularly shaped particles (Figs. 1 and 2). These results confirmed that capsid formation is necessary to achieve high virus accumulation in upper noninoculated leaves. These results also suggested that large deletions at the $\mathrm{N}$ terminus of CP may affect protein folding and the ability to efficiently form viral particles. To minimize the impact of deletions on protein folding and stability, we further characterized only alanine scanning mutants, which were all able to form regularly shaped particles.

\section{Effects of mutations in the KR region on host range.}

We next tested the ability of OuMV CP alanine mutants to systemically infect several plant species that are normally susceptible to OuMV $\mathrm{wt}_{\mathrm{wt}}$. We agroinfiltrated lower leaves and monitored the appearance of symptoms on systemically infected upper leaves and the accumulation of CP by Western blot analysis. We focused mainly on cucurbits, which are natural hosts of OuMV, but also tested $N$. tabacum, which is more resistant to OuMV infection than Cucumis melo 'Retato', C. sativus, and $N$. benthamiana (Table 1). Mutations in the KR region of $\mathrm{CP}$ strongly affected the pathogenicity in more restrictive hosts, as assessed by the proportion of systemically infected

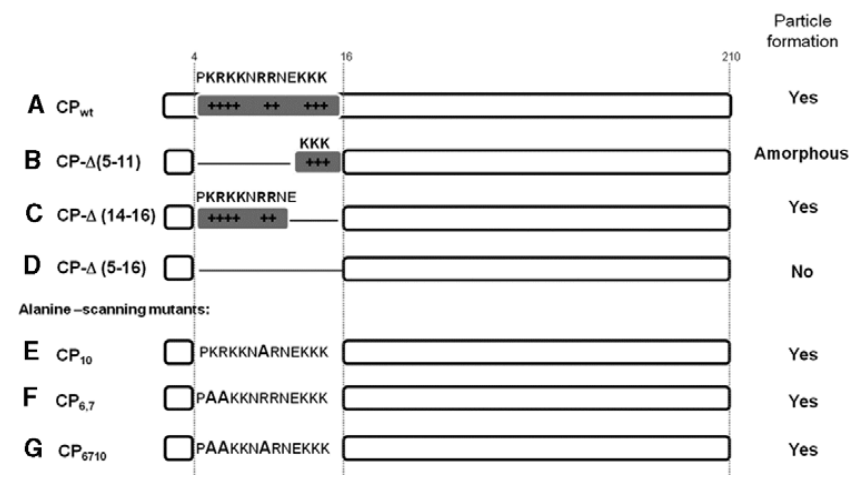

Fig. 1. Schematic representation of the constructs used in this study. The white boxes correspond to the coat protein (CP) sequence, the dark gray boxes highlight the protein region rich in lysine/arginine (KR) residues, and the symbol "+" corresponds to positively charged amino acids. The ability of the mutants to form capsids during viral infection is reported for each construct. plants versus inoculated plants. Even a single alanine substitution strongly affected the ability of the mutant R10A $\left(\mathrm{OuMV}_{10}\right)$ to systemically infect $C$. melo and $N$. tabacum and partially affected the pathogenicity on $C$. sativus. Similar results have been obtained with the double mutant K6A,R7A $\left(\mathrm{OuMV}_{6,7}\right)$. However, the triple mutant K6A,R7A,R10A $\left(\mathrm{OuMV}_{6710}\right)$ completely lost the ability to systemically infect not only N. tabacum but also all the cucurbit species and cultivars tested in this experiment. Single and multiple alanine substitutions at the $\mathrm{N}$ terminus of $\mathrm{CP}$ affected also severity of symptoms on leaves (Fig. 3A). The differential ability of these mutants to infect different plant species was mirrored by differences in their $\mathrm{CP}$ accumulation in noninoculated leaves. In fact, the presence or absence of symptoms in cucurbit species correlated strictly with the presence or absence of CP in Western blot analyses (Fig. 3B). In $N$. benthamiana plants, in which all mutants tested could accumulate systemically, the $\mathrm{CP}$ was always detected; although, in the case of $\mathrm{OuMV}_{6710}$, the $\mathrm{CP}$ accumulation was strongly reduced (Fig. 3B). In summary, the ability to systemically infect different susceptible species was reduced or disappeared completely with the increasing number of substitutions into the $\mathrm{CP} \mathrm{N}$-terminal region. Because the triple mutation gave the most striking effects, we decided to concentrate our attention on $\mathrm{OuMV}_{6710}$.

\section{OuMV $_{6710}$ virion formation is not affected quantitatively but encapsidation of genomic RNA is impaired.}

To determine whether alanine substitutions in the KR region affect the ability of the mutant $\mathrm{CP}$ to self-interact to form virions, we quantified the $\mathrm{CP}$ by double-antibody sandwich enzyme-linked immunosorbent assay (DAS-ELISA) in N. benthamiana noninoculated leaves infected by $\mathrm{OuMV}_{\mathrm{wt}}$ and OuMV $_{6710}$, then estimated the number of particles present in each sample through observations of virus particles in serial dilutions by electron microscopy (EM). In these experiments,
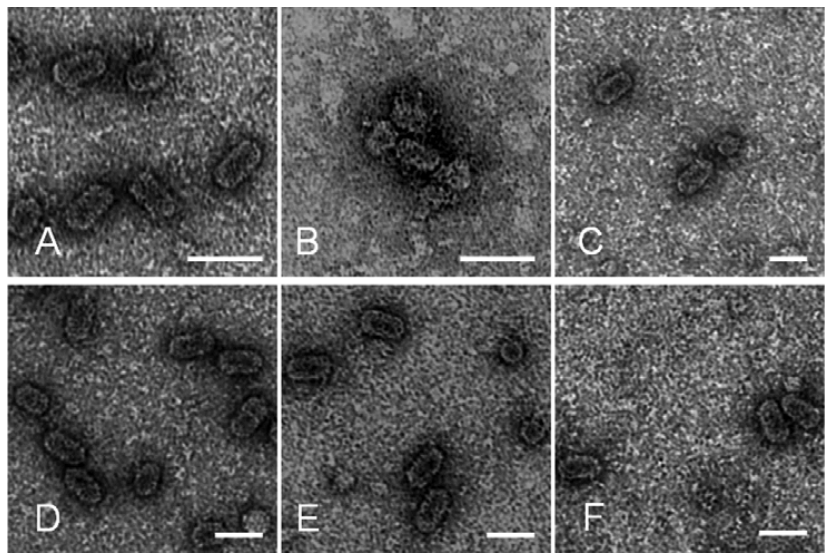

Fig. 2. Competence for virion formation. Electron micrograph of negatively stained immunosorbent electron microscopy preparations of sap from agroinfiltrated Nicotiana benthamiana leaves collected 3 days postinoculation. $\mathbf{A}, \mathrm{CP}_{\mathrm{wt}} ; \mathbf{B}, \mathrm{CP}_{\Delta(5-11)} ; \mathbf{C}, \mathrm{CP}_{\Delta(14-16)} ; \mathbf{D}, \mathrm{CP}_{10} ; \mathbf{E}, \mathrm{CP}_{6,7} ; \mathbf{F}$, $\mathrm{CP}_{6710}$. Bars $=50 \mathrm{~nm}$.

Table 1. Number of systemically infected plants out of total number of inoculated plants ${ }^{\mathrm{a}}$

\begin{tabular}{|c|c|c|c|c|c|c|c|c|c|c|}
\hline \multirow[b]{2}{*}{ Virus } & \multicolumn{2}{|c|}{ Nicotiana benthamiana } & \multicolumn{2}{|c|}{ N. tabacum } & \multicolumn{2}{|c|}{ Cucumis melo 'Vendrantais' } & \multicolumn{2}{|c|}{ C. sativus } & \multicolumn{2}{|c|}{ C. melo 'Retato' } \\
\hline & 14 dpi & 21 dpi & 14 dpi & 21 dpi & 14 dpi & 21dpi & 14 dpi & 21dpi & 14 dpi & 21 dpi \\
\hline $\mathrm{OuMV}_{\mathrm{wt}}$ & $4 / 4$ & $4 / 4$ & $1 / 4$ & $2 / 4$ & $2 / 5$ & $2 / 5$ & $6 / 6$ & $6 / 6$ & $4 / 4$ & $4 / 4$ \\
\hline OuMV $_{10}$ & $4 / 4$ & $4 / 4$ & $0 / 4$ & $0 / 4$ & $0 / 4$ & $0 / 4$ & $4 / 6$ & $4 / 6$ & $0 / 5$ & $0 / 5$ \\
\hline OuMV $_{6,7}$ & $4 / 4$ & $4 / 4$ & $0 / 4$ & $0 / 4$ & $0 / 6$ & $0 / 6$ & $5 / 6$ & $5 / 6$ & $0 / 4$ & $0 / 4$ \\
\hline OuMV $_{6710}$ & $4 / 4$ & $4 / 4$ & $0 / 9$ & $0 / 9$ & $0 / 5$ & $0 / 5$ & $0 / 6$ & $0 / 6$ & $0 / 4$ & $0 / 4$ \\
\hline
\end{tabular}

a Abbreviations: dpi = days postinoculation and OuMV = Ourmia melon virus. 
we consistently observed a linear correlation between $\mathrm{CP}$ abundance and the number of viral particles in plants infected with $\mathrm{OuMV}_{\mathrm{wt}}$ and $\mathrm{OuMV}_{6710}$ (Fig. 4A).

To evaluate the encapsidation efficiency of $\mathrm{CP}_{\mathrm{wt}}$ and $\mathrm{CP}_{6710}$ in vivo, we purified viral particles from infected $N$. benthamiana noninoculated leaves. The CP titers of the purified particles were measured by DAS-ELISA and confirmed by counting the number of virions per milliliter of purified extract through direct EM observation. OuMV genomic RNA was extracted from the same amount of viral particles and quantitative reverse-transcriptase polymerase chain reaction (PCR) was performed, and these experiments revealed that OuMV $_{6710}$ particles had a genomic RNA content 13.7 times lower than OuMV $_{\text {wt. }}\left(0.9 \pm 0.1\right.$ and $12.4 \pm 2.6$ units for $\mathrm{OuMV}_{6710}$ and OuMV $_{\mathrm{wt}}$, respectively). To confirm this result, the purified virions (whole viral particles) were also run on agarose gel in Tris glycine buffer (which maintains virion structure throughout the run), transferred onto two distinct membranes, and subjected to Northern and Western analysis using an RNA3 probe and an

A
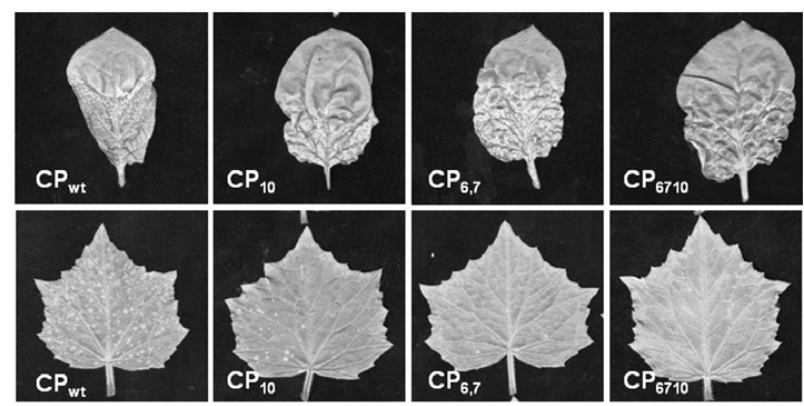

B

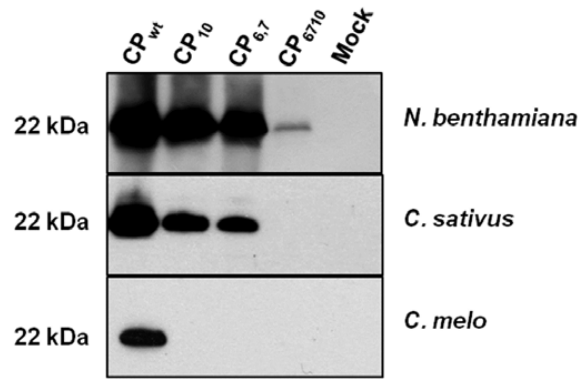

Fig. 3. Effects of alanine substitution on coat protein (CP) accumulation and symptom severity. A, Symptom severity induced by OuMV wild-type and mutant strains on noninoculated leaves of Nicotiana benthamiana (upper panels) and Cucumis sativus (lower panels). B, Western blot analysis of $\mathrm{CP}$ accumulation in noninoculated leaves in infected plants of $N$. benthamiana, C. sativus, and C. melo.
anti-CP antibody, respectively. Loading 10 times more whole particles of $\mathrm{OuMV}_{6710}$ than $\mathrm{OuMV} \mathrm{vt}_{\mathrm{wt}}$ was required to produce similar amounts of signal in the RNA hybridization experiment (Fig. 4B).

Effects of mutations in the KR region on recovery in $N$. benthamiana: symptom severity was maintained but virus was not detected.

$N$. benthamiana plants agroinfiltrated with the infectious $\mathrm{OuMV}_{\mathrm{wt}}$ and OuMV 6710 clones were monitored over a 5-week period after inoculation for symptom severity and virus accumulation, to study the effect on recovery. When the symptoms first appeared at approximately 7 days postinoculation (dpi), the $\mathrm{CP}_{\mathrm{wt}}$ accumulation level in systemic leaves was approximately 10 times higher than the $\mathrm{CP}_{6710}$ triple mutant (Fig. 5A). The symptom severity was also correlated with differences in $\mathrm{CP}$ accumulation: in fact, $\mathrm{OuMV}_{\mathrm{wt}}$ induced a strong extended necrosis localized mainly at the leaf base, whereas $\mathrm{OuMV}_{6710}$ induced milder symptoms on the whole leaf blade, and infection foci at the exit site remained limited (Fig. 5B). By 21 dpi, a drastic reduction of $\mathrm{OuMV}_{\mathrm{wt}}$ accumulation had occurred, reaching a titer similar to that of the mutant (Fig. 5A). At 28 and 35 dpi, OuMV $\mathrm{wt}_{\mathrm{wt}}$ had a low accumulation rate and no symptoms were detected on the new leaves. In contrast, in OuMV $\mathrm{V}_{6710^{-}}$ infected plants, the young leaves appeared symptomatic with necrotic lesions (Fig. 5B) but, surprisingly, virus could not be detected in these leaves (Fig. 5A).

The potential role of the $\mathrm{CP}_{\mathrm{wt}}$ protein as a silencing suppressor is not revealed by a standard bioassay on transgenic $16 \mathrm{C} N$. benthamiana.

Because recovery from viral infection in plants is related to plant defense and mainly due to RNA silencing activity (Jovel et al. 2007), we decided to investigate whether suppression of host gene silencing is involved in virulence differences between the two strains. A classical test for revealing silencing suppressor activity was initially performed by co-agroinfiltrating 16C N. benthamiana with pBin-GFP (Margaria et al. 2007) and each of the pBin61 derivatives of OuMV RdRp, MP, and CP previously described (Crivelli et al. 2011). As positive control, we used the well-characterized silencing suppressor p19 of Tomato bushy stunt virus (TBSV), which exhibited suppression, but we failed to detect suppression activity with the OuMV MP, CP, or RdRp (not shown). However, in this assay, RNA2 and RNA3 were agroinfiltrated alone using a pBin61 backbone (Crivelli et al. 2011) and the corresponding proteins were expressed to much lower levels than those occurring during virus infection. The low accumulation of $\mathrm{MP}$ and $\mathrm{CP}$ could
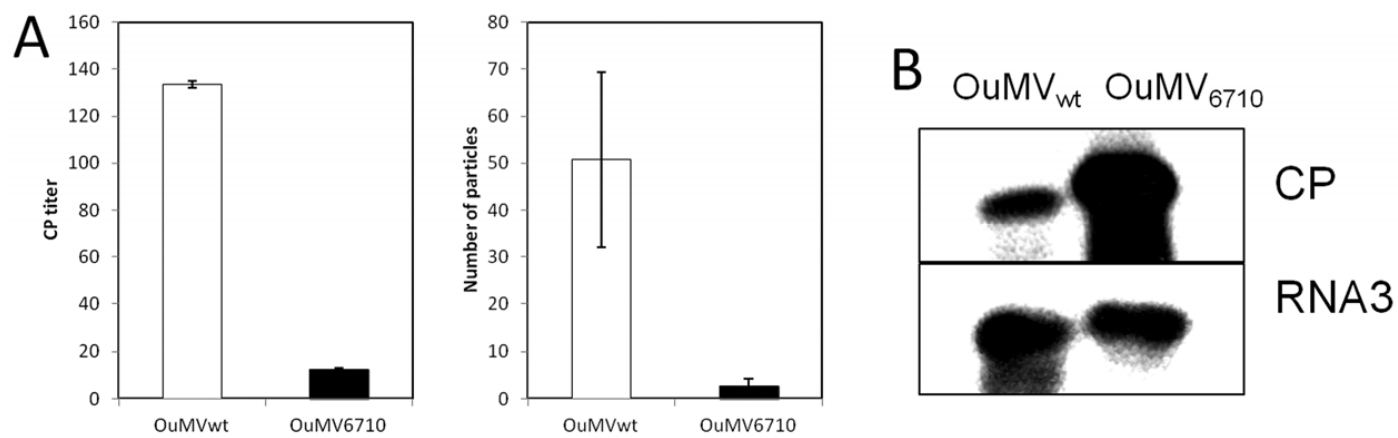

Fig. 4. Correlation among coat protein (CP) titer, virus particles, and RNA encapsidation in infected Nicotiana benthamiana plants 7 days postinoculation A, OuMV $V_{w t}$ and OuMV $V_{6710} \mathrm{CP}$ titer measured by double-antibody sandwich enzyme-linked immunosorbent assay (left chart) and corresponding number of particles counted at the electron microscope (right chart). B, OuMV $\mathrm{wt}_{\mathrm{t}}$ and $\mathrm{OuMV}_{6710}$ virus particle titer measured by Western blot (top panel) and corresponding amount of encapsidated viral RNA measured by Northern blot (bottom panel). Statistical analysis was performed using $t$ test $(P>0.05)$. Error bars represent the standard deviations. 
explain the observed lack of silencing suppression; therefore, for this reason, we repeated the experiment with replicationcompetent constructs expressing RNA2 and RNA3 with RNA1 (Supplementary Fig. S1) (pGC-RNA1, pGC-RNA2, and pGCRNA3, as described by Crivelli and associates [2011]). Yet, again, we did not observe increases in GFP expression with any of the tested combinations, either by directly observing leaves under UV light or by Western blotting.

Nevertheless, another indication of the involvement of a protein in specific antiviral silencing suppression can be inferred from alternative genetic approaches: viral mutants compromised in their silencing suppressor activity can be complemented either using Dicer-like (DCL) defective host plants (e.g., Arabidopsis thaliana plants) or by providing a silencing suppressor in trans. Experiments using these strategies are described below. To use the well-characterized A. thaliana Dicer mutants, we first tested the ability of OuMV $V_{w t}$ and $O u M V_{6710}$ to infect this plant.

\section{$\mathrm{OuMV}_{\mathrm{wt}}$ and $O u M V_{6710}$ can infect $A$. thaliana.}

To determine whether A. thaliana is a host for OuMV, different agroinfection protocols were first attempted but they all failed (not shown); therefore, we infected plants by mechanical inoculation. The inoculum for mechanical inoculation was standardized on the basis of the differential accumulation of $\mathrm{CP}$ (and virions) in infected $N$. benthamiana. Given that OuMV $_{6710}$ accumulates only to $10 \%$ of the levels of the OuMV $_{\text {wt }}$, we diluted OuMV $V_{\text {wt }}$ sap 1:10 in healthy N. benthamiana, while the OuMV 6710 sap was kept undiluted. Comparisons of the numbers of local lesions observed on $N$. benthamiana inoculated at the same time as A. thaliana provided a good test of the relative infectivities of the two inocula (not shown). With equal virus titers in the inoculation source, the OuMV $_{6710}$ mutant had reduced ability to infect Arabidopsis WT plants systemically (only three of nine plants at 14 dpi became systemically infected) (Table 2), and these developed milder symptoms than OuMV ${ }_{\mathrm{wt}}$. Furthermore, the virus titer in the infected plants was 10 times lower in $\mathrm{OuMV}_{6710}$ than $\mathrm{OuMV}_{\mathrm{wt}}$ infections, as observed in N. benthamiana (Fig. 6C).

\section{A potential role of the $\mathrm{CP}_{\mathrm{wt}}$ protein}

as a silencing suppressor is suggested

by increased small interfering (si)RNA accumulation

in $A$. thaliana infected with the OuMV 6710 mutant.

The accumulation of viral RNAs and siRNAs derived from Dicer activity was monitored in infected Col- 0 plants by Northern blot analysis (Fig. 6A and B). As expected from DASELISA results, accumulation of viral genomic RNA1 and RNA3 was impaired in plants infected with $\mathrm{OuMV}_{6710}$ (Fig. 6A). To investigate whether this was a consequence of a compromised silencing suppression capability of $\mathrm{OuMV}_{6710}$, we analyzed the accumulation of siRNA derived from RNA3. In experiments in which the same amounts of genomic RNA3 were loaded, we detected an accumulation of siRNA derived from RNA3 that was five to 10 times higher in $\mathrm{OuMV}_{6710^{-}}$infected plants than in OuMV $\mathrm{wt}_{\mathrm{w}}$ virus infections (Fig. 6B).

\section{A role of the $\mathrm{CP}_{\mathrm{wt}}$ protein in contrasting antiviral defense} is confirmed in A. thaliana dcl2/dcl4 mutants and in p19. expressing $N$. benthamiana.

The potential involvement of the OuMV CP in silencing suppression was studied in more detail by using Arabidopsis Dicer-like mutants, which are knock-out lines lacking genes encoding for Dicer proteins and, hence, defective in silencing activity. Interestingly, the phenotype of $\mathrm{CP}_{6710}$ was complemented in $d c l 2 / d c l 4$ and $d c l 2 / d c l 3 / d c l 4$ : symptom severity, number of infected plants, and virus titer were comparable

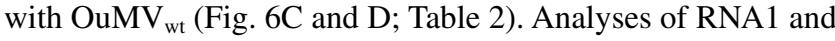
RNA3 accumulation also revealed increased amounts of $\mathrm{OuMV}_{6710}$ in Dicer-like defective $d c l 2 / d c l 4$ mutant compared with Col-0 (Fig. 6A). No effects on viral genomic accumulation of the $\mathrm{CP}_{6710}$ mutant was observed in $d c l 1$ and $d c l 2 / d c l 3$ plants, and this finding is in agreement with current literature on antiviral activity of the different DCL proteins (Fig. 6A).

To obtain further indications on the putative role of the OuMV CP as a suppressor of antiviral defenses, we measured OuMV CP accumulation in agroinfiltrated $N$. benthamiana leaves in the presence or absence of the p19 silencing suppressor. We only used RNA1 and RNA3 in order to measure accu-
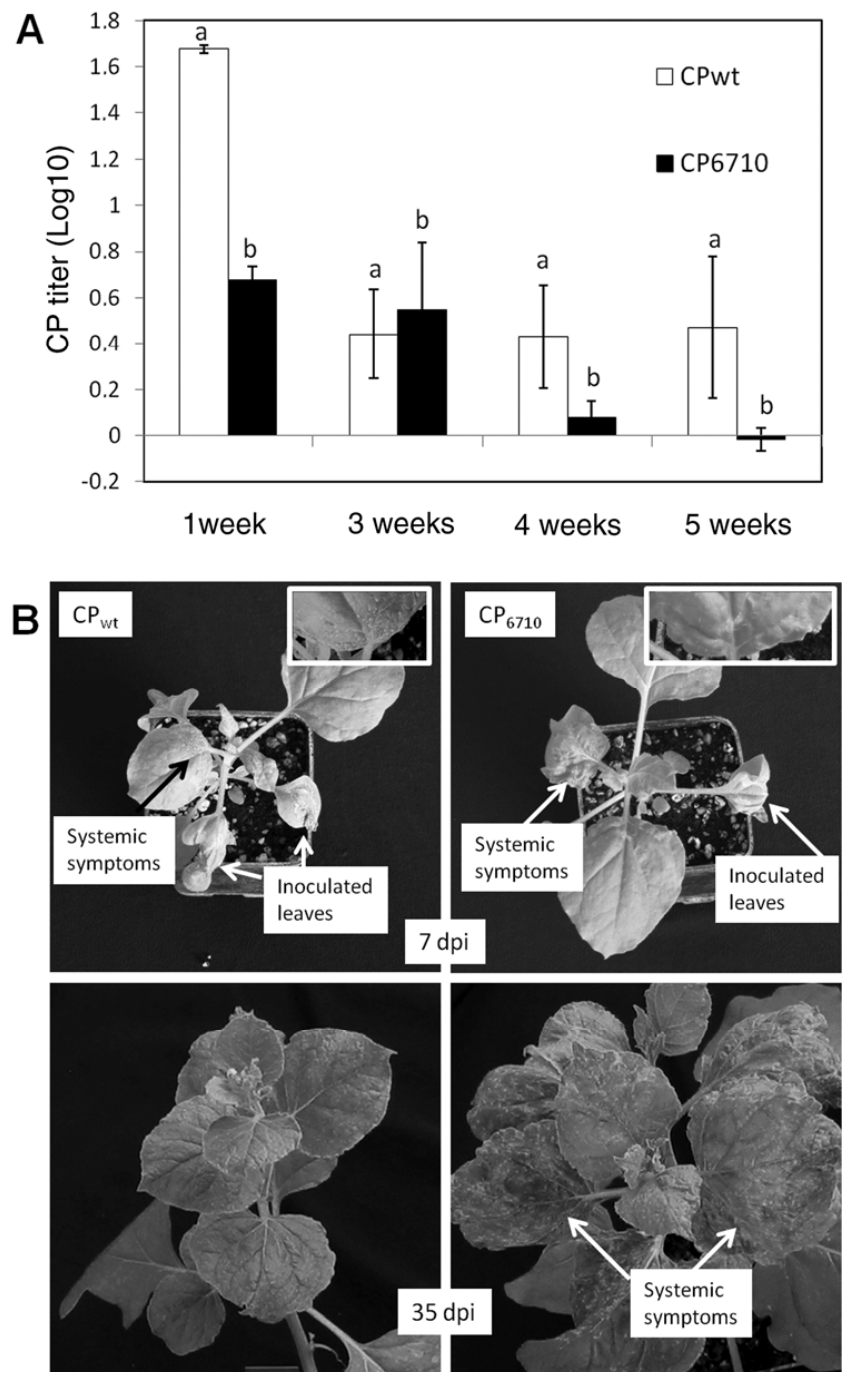

Fig. 5. Recovery from viral infection. A, Coat protein (CP) accumulation in $\mathrm{OuMV}_{\mathrm{wt}}$ and OuMV 6710 Nicotiana benthamiana-infected leaves measured during a 5-week time course by double-antibody sandwich enzymelinked immunosorbent assay. The titer is expressed as $\log _{10}$ of the relative value calculated on a standard dilution curve. Data reported are the mean values of five plants and three independent experiments. Statistical analysis was performed using $t$ test $(P>0.05)$. Different letters represent significantly different results. Error bars represent the standard deviations. B, Systemic symptoms on $N$. benthamiana infected with $\mathrm{OuMV}_{\mathrm{wt}}$ (left panels) and $\mathrm{OuMV}_{6710}$ (right panels) at 7 and 35 days postinoculation.

Table 2. Number of systemically infected Arabidopsis plants out of total number of mechanically inoculated plants 14 days postinoculation

\begin{tabular}{lccc}
\hline Virus & Col-0 & dcl2/dcl4 & dcl2/dcl3/dcl4 \\
\hline OuMV $_{\mathrm{wt}}$ & $8 / 9$ & $9 / 9$ & $9 / 9$ \\
OuMV $_{6710}$ & $3 / 9$ & $9 / 9$ & $9 / 9$ \\
\hline
\end{tabular}


mulation in initially infected cells, thereby eliminating artifacts that might result from differential virus movement. Accumulation was measured at 6 days postagroinfiltration in order to permit the amount of $\mathrm{CP}$ due to viral replication to increase and minimize the contribution of the initial transcription from the binary vector. In the case of strain $\mathrm{OuMV}_{\mathrm{wt}}$, the presence of p19 did not significantly increase accumulation; whereas, in the case of $\mathrm{OuMV}_{6710}$, the increase was statistically significant, although it was not sufficient to fully complement the initial defect (Fig. 7).

Different tissue tropisms revealed

by immunolocalization of $\mathbf{C P}_{\mathrm{wt}}$ and $\mathbf{C P}_{6710}$

in OuMV-infected $N$. benthamiana and $A$. thaliana.

Immunolocalization experiments on infected leaf sections showed that the $\mathrm{CP}_{\mathrm{wt}}$ formed large aggregates, whereas the

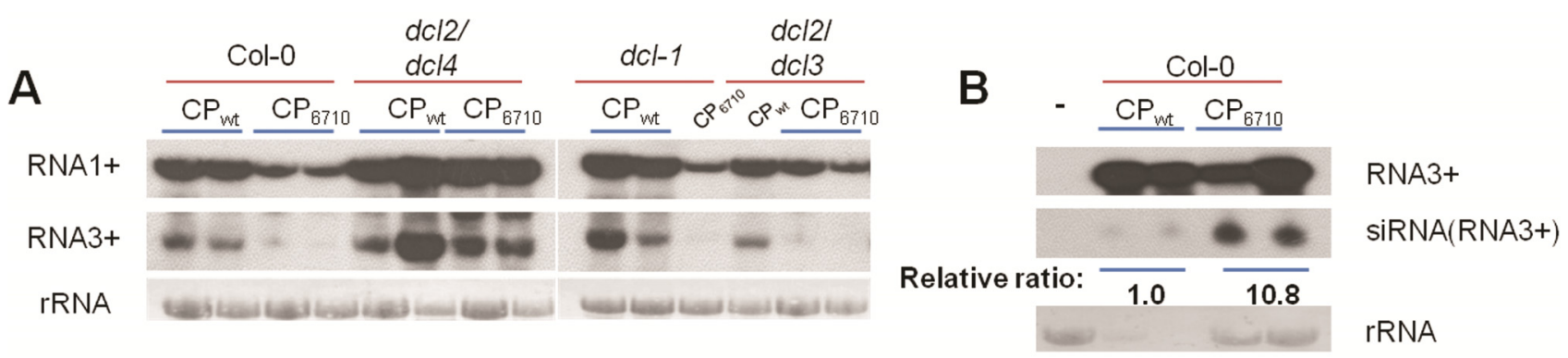

C
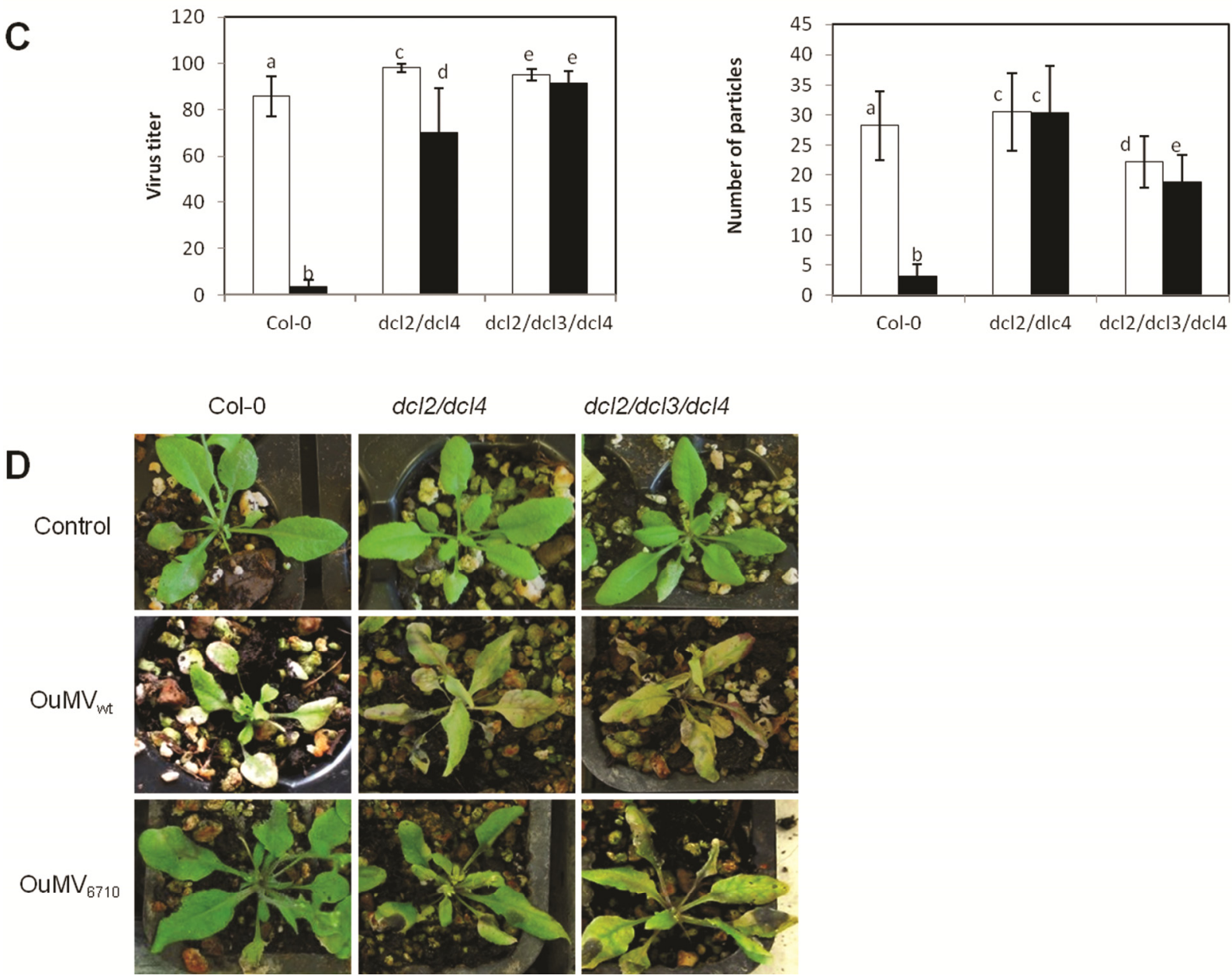

Fig. 6. Comparison of OuMV $\mathrm{wt}_{\text {and }}$ OuMV ${ }_{6710}$ genomic RNA, small RNA, and particle accumulation and symptom severity in wild-type and Dicer-defective Arabidopsis thaliana. A, Northern blot analysis of viral RNA accumulation in A. thaliana Col-0 and Dicer-defective lines 7 days postinoculation (dpi) with OuMV $_{\mathrm{wt}}$ and OuMV 6710 . Equal amounts of total RNA were loaded. The top panel shows the plus-strand RNA1, the second panel the plus-strand RNA3, and the bottom panel the rRNA stained with bromophenol blue. B, Northern blot analysis of the accumulation of small interfering (si)RNA derived from RNA3

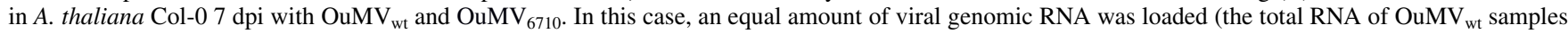
had to be diluted 1/10). The top panel shows the plus-strand RNA3, the second panel the siRNA from plus-strand RNA3, and the bottom panel the rRNA stained with bromophenol blue. The relative ratio was calculated as ratio between the intensity of siRNAs bands of OuMV 6710 and OuMV $\mathrm{V}_{\mathrm{wt}} \mathbf{C}_{\text {, }}$. thaliana Col-0, dcl2/dcl4, and $d c l 2 / d c l 3 / d c l 4$ plants 7 dpi infected with OuMV $\mathrm{wt}_{\text {t }}$ and OuMV 6710 virus titer measured by double-antibody sandwich enzyme-linked immunosorbent assay (left panel) and number of particles counted at the electron microscope (right panel). Data reported are the mean values of five independent experiments. Statistical analysis was performed using $t$ test $(P>0.05)$. Different letters represent significantly different results. Error bars represent the standard deviations. D, Symptom severity on Col-0, $d c l 2 / d c l 4$, and $d c l 2 / d c l 3 / d c l 4$ lines infected with OuMV $\mathrm{wt}_{\mathrm{w}}(\mathrm{middle}$ panel), OuMV $6710(\mathrm{bottom}$ panel), and noninoculated control (top panel) 7 dpi. 
mutant displayed a less intense and more diffuse signal that may be explained by lower $\mathrm{CP}$ accumulation (Fig. 8). Interestingly, in both $N$. benthamiana and Arabidopsis, we noticed differential accumulation in different tissues within the leaf, and

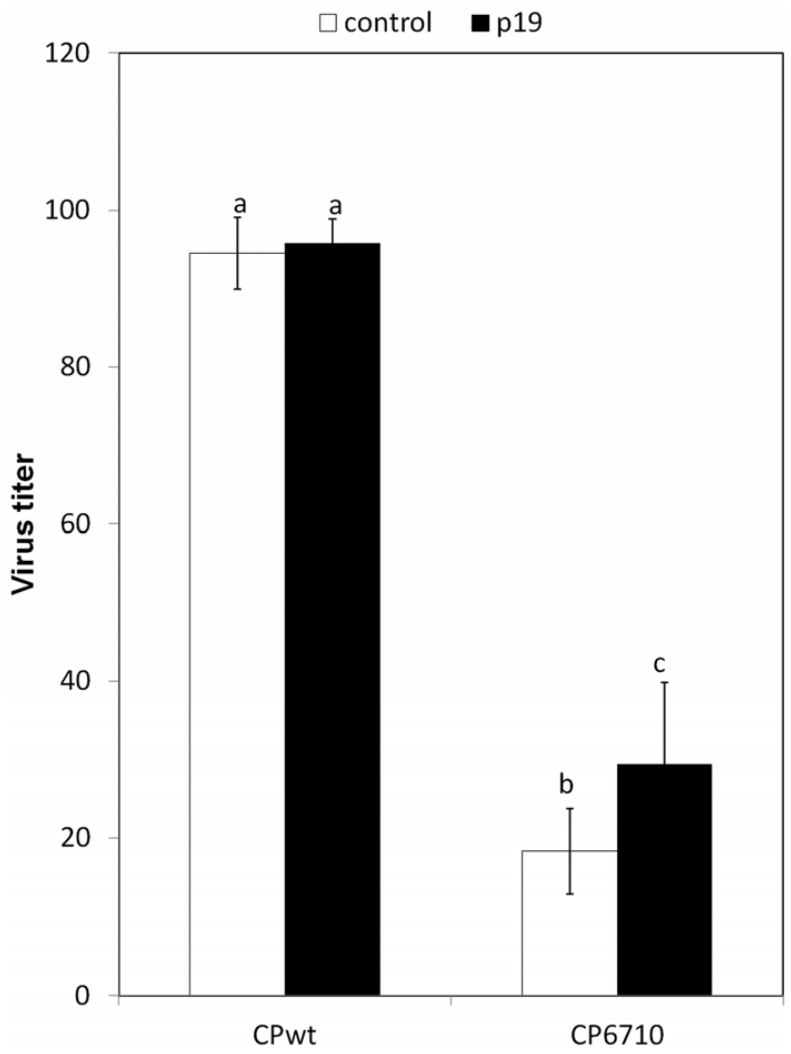

Fig. 7. Effect of p19 expression on virus accumulation in Nicotiana benthamiana. Virus titer was measured with double-antibody sandwich enzymelinked immunosorbent assay for coat protein (CP). Data reported are the mean values of 12 plants and three independent experiments. Statistical analysis was performed using $t$ test $(P>0.05)$. Different letters represent significantly different results. Error bars represent the standard deviations. speculated that this is due to different tissue tropisms between the two strains (Figs. 9 and 10). In particular, the WT virus was able to accumulate equally in spongy and palisade mesophyll, whereas the triple mutant was mostly present in the spongy mesophyll and only occasionally accumulated in the palisade tissue. Surprisingly, the ability of the $\mathrm{OuMV}_{6710}$ strain to efficiently infect the palisade mesophyll was restored in the dcl2/dcl4 mutant (Fig. 10). In these leaves, the mutant accumulated equally throughout the mesophyll tissue, suggesting that the silencing machinery can differentially influence virus accumulation in a tissue-specific manner.

\section{DISCUSSION}

CP of icosahedral positive-strand RNA viruses lack a commonly conserved sequence homology but share structural analogies. With few exceptions, CP monomers have a protruding and flexible N-terminal arm (NTA), a central core called the shell (S) domain, and, in most cases, a C-terminal projecting domain (P) (Dolja and Koonin 1991; Rossmann and Johnson 1989). The NTA are usually oriented toward the internal lumen of the capsid and they are frequently rich in positively charged residues (Guerra-Peraza et al. 2005; Hsu et al. 2006; Hu and Ghabrial 1995; Lee and Hacker 2001; Olspert et al. 2010; Rao and Grantham 1995; Reade et al. 2010; Sharma and Ikegami 2009; Yusibov and Loesch-Fries 1995). Due to their structural and molecular characteristics, the NTA may have different roles such as encapsidation, interaction between $\mathrm{CP}$ and viral genomic RNA, viral movement, and pathogenicity (Herranz et al. 2011; Ruiz-Ruiz et al 2013; Kaplan et al. 1998; Palani et al. 2006; Qi et al. 2008; Schmitz and Rao 1998). OuMV CP has a typical NTA region containing a KR region and, here, we have characterized a number of viral properties dependent on its integrity.

\section{The NTA of OuMV CP has a role} in genomic RNA encapsidation in vivo.

An OuMV CP mutant lacking the entire KR region was unable to form capsids, whereas shorter deletions in the same protein region permitted capsid formation but strongly altered
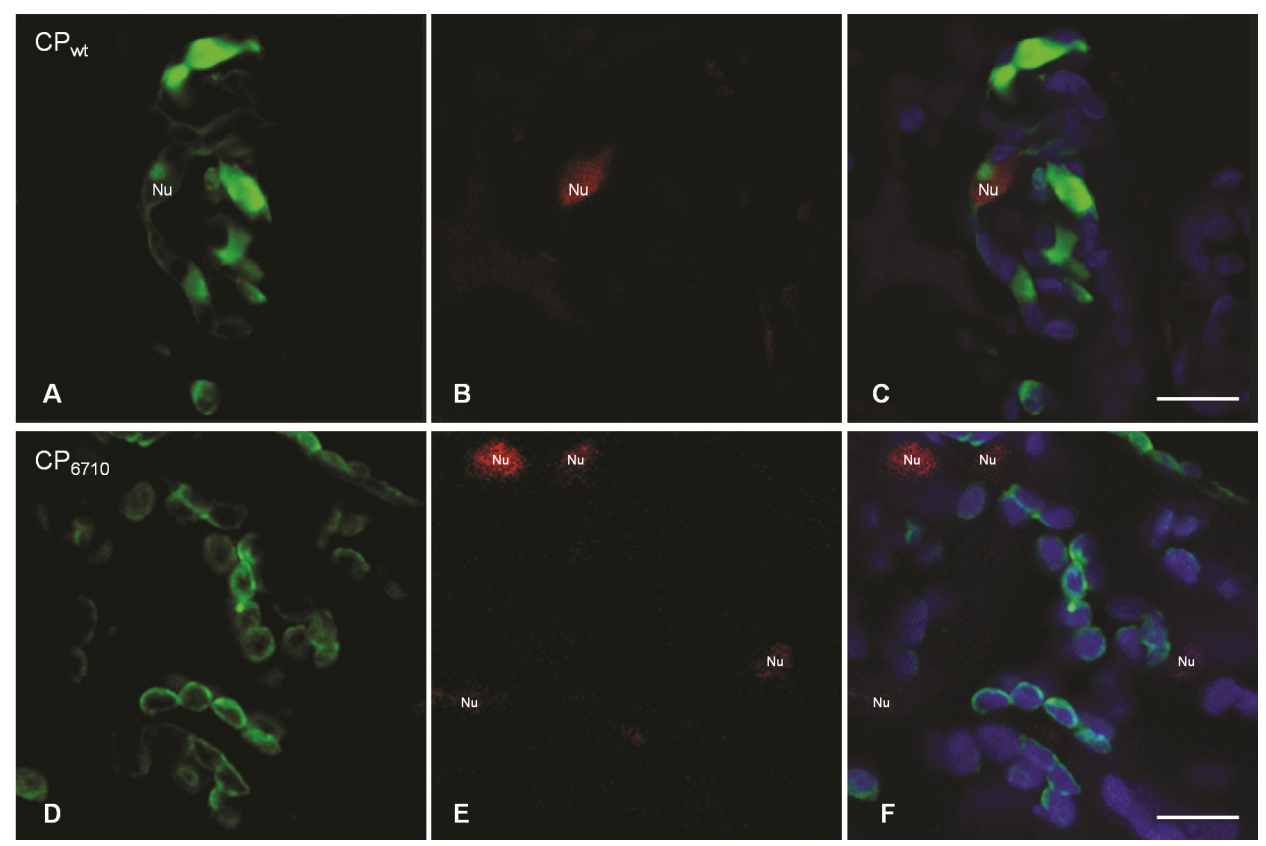

Fig. 8. Immunolocalization of OuMV $\mathrm{CP}_{\mathrm{wt}}$ and $\mathrm{CP}_{6710}$ in transversal sections of Nicotiana benthamiana leaf cells. $\mathbf{A}$ and $\mathbf{D}$, Fluorescent signal of fluorescein isothiocyanate-conjugated, specific for $\mathrm{CP}$ detection; $\mathbf{B}$ and $\mathbf{E}$, nuclei ( $\mathrm{Nu}$ ) visualized after staining with 4',6-diamidino-2-phenylindole (in red); $\mathbf{C}$, overlay of A and B and the fluorescent signal of chlorophyll (blue); F, overlay of D and E and the fluorescent signal of chlorophyll (blue). Bars $=20 \mu \mathrm{m}$. 
capsid shape. However, alanine substitutions that reduced or neutralized the positive charges within the KR region did not affect the ability to form viral particles, suggesting that the spatial or structural integrity but not the charge of this protein region is needed for capsid assembly. In particular, it seems that the triple amino acid substitution in the $\mathrm{CP}_{6710}$ mutant did not alter the efficiency of virion assembly, because the number of particles present in OuMV 6710 -infected plants was proportional to the amount of $\mathrm{CP}$ accumulated in the same plant, as was also observed during $\mathrm{OuMV}_{\mathrm{wt}}$ infections. However, using two different approaches to measure the amount of RNA encapsidated in standardized quantities of virions, we found that the $\mathrm{CP}_{6710}$ mutant had a 10 -fold reduced RNA encapsidation capacity compared with the WT. This finding provides evidence for an involvement of OuMV CP NTA in the interactions between the CP and viral genomic RNA. A similar situation also exists with Brome mosaic virus (BMV) $\mathrm{CP}$, in which the positive charges within the NTA contribute to RNA binding, and mutations within this region can result in changes in the amounts and species of encapsidated viral RNA, suggesting that the NTA recruits RNA molecules by a combination of specific recognition and nonspecific electrostatic binding ( $\mathrm{Ni}$ et al. 2012).

\section{The NTA of OuMV CP is a host range determinant.}

In OuMV infections of members of the Solanaceae and Cucurbitaceae families, we observed reductions in symptom severity and a narrowing of the host range with increased numbers of amino acid substitutions within the KR region. It is known that the NTA of several virus CP have roles in determining host range and in modulating symptom severity (Callaway et al. 2001; Carbonell et al. 2013). The arginine-rich NTA of the BMV CP, for instance, is a pathogenicity determinant, and truncations within this domain lead to altered symptomatology in some plant species (Rao and Grantham 1995, 1996). The N terminus of the $\mathrm{CP}$ of Plum pox virus (PPV) also contains a host-specific pathogenic determinant that is also fundamental for efficient systemic virus movement (Carbonell et al. 2013). Mutations within this region can compromise PPV systemic movement in different hosts and reduce the host range (Carbonell et al. 2013). Viruses need to move from cell to cell to achieve optimal local infections, and transit long-distances though the vascular system to guarantee systemic spread of infections. More often than for cell-to-cell movement, CP play a key role in long-distance transport of viruses (Scholthof 2005). Tobamoviruses and dianthoviruses, for instance, need $\mathrm{CP}$ for long-distance but not for local movement (Callaway et al. 2001). The potyvirus family member Tobacco etch virus (TEV) requires the $\mathrm{CP}$ for local and systemic movement, and it has been shown that certain mutations in the TEV CP permit local movement but block long-distance virus spread (Callaway et al. 2001; Dolja et al. 1994, 1995). Furthermore, in Carnation ringspot virus, a single amino acid mutation blocks virus systemic movement without affecting capsid formation (Sit et al. 2001). A deficiency in movement capability could explain differences in symptom severity and altered host range of OuMV, because mutations within the $\mathrm{CP} \mathrm{N}$-terminal region might specifically affect virus movement more severely in cucurbits than in $N$. benthamiana.

\section{The NTA of OuMV CP is involved in tissue tropism.}

The types of cells and tissues that can be infected by viruses define their tissue tropisms, which are often determined by specific viral factors. For example, Bean golden mosaic virus is able to infect $N$. benthamiana systemically but the infection remains limited to the phloem. However, in the same host, the closely related Tomato golden mosaic virus (TGMV) efficiently infects not only the phloem but also mesophyll cells (Morra and Petty 2000). In immunolocalization experiments, we showed that amino acidic substitutions within the OuMV CP NTA strongly influenced virus tissue tropism in N. bethamiana and A. thaliana. OuMV $\mathrm{wt}_{\mathrm{w}}$ was able to infect the whole leaf tissue efficiently, whereas $\mathrm{OuMV}_{6710}$ could spread in the spongy mesophyll but only occasionally move to the palisade. It has been suggested previously that tissue tropism may result from interactions between the plant defense system and viral silencing suppressors (Voinnet et al. 1999). For example, the $2 \mathrm{~b}$ silencing suppressor protein of Cucumber mosaic virus

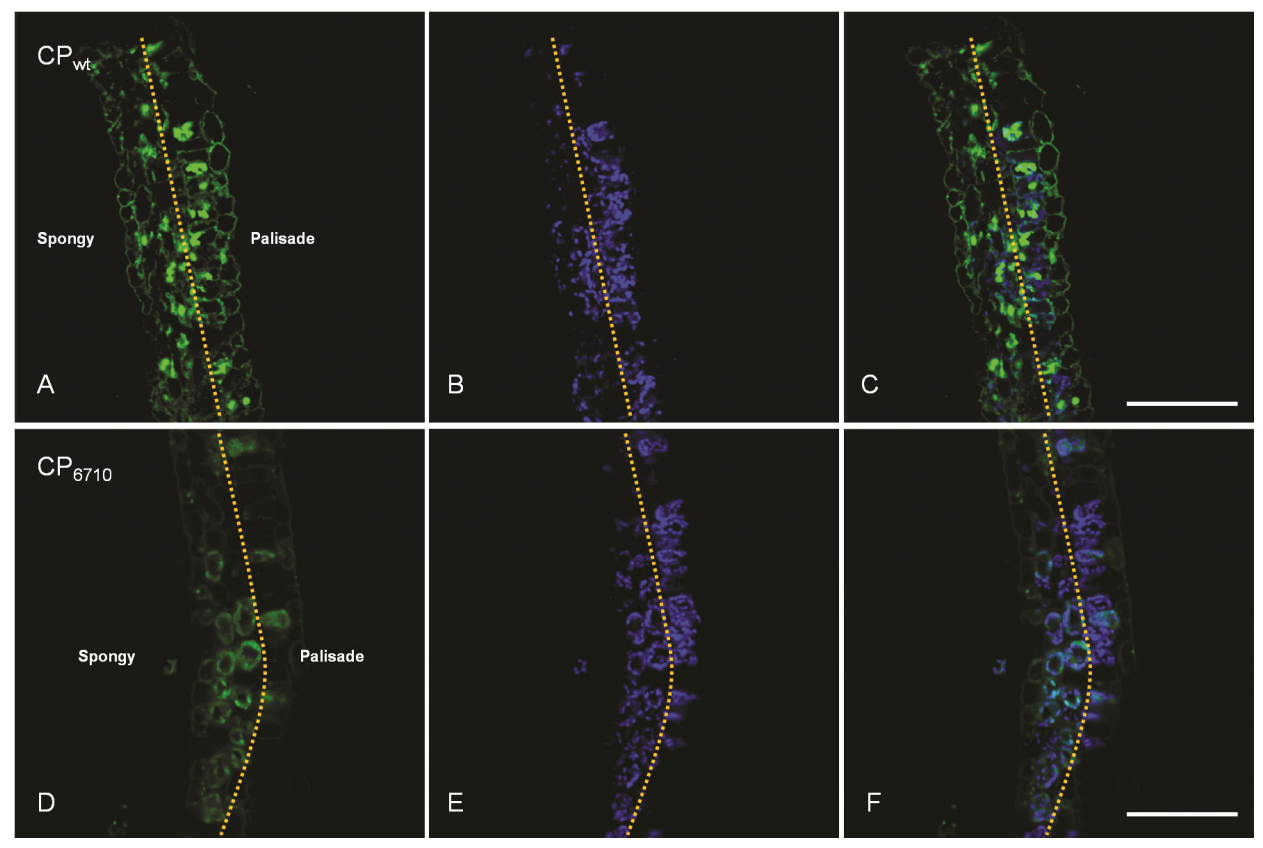

Fig. 9. Immunolocalization of OuMV coat protein $(\mathrm{CP})$ in transversal sections of Nicotiana benthamiana leaves infected with $\mathrm{OuMV}_{\mathrm{wt}}$ and OuMV 6710 . A and $\mathbf{D}$, Fluorescent signal of fluorescein isothiocyanate-conjugated, specific for CP detection; $\mathbf{B}$ and $\mathbf{E}$, Fluorescent signal of chlorophyll (blue); $\mathbf{C}$, overlay of $\mathrm{A}$ and $\mathrm{B} ; \mathbf{F}$, overlay of D and E. Dotted lines indicate the boundary between spongy and palisade tissue. Bars $=100 \mu \mathrm{m}$. 
(CMV) is necessary for the efficient virus invasion of leaf tissues (Soards et al. 2002) and is responsible for tissue-specific tropism. The WT CMV can, in fact, equally infect epidermal and mesophyll cells, whereas the $\Delta 2 \mathrm{~b}$ strain can spread efficiently in the mesophyll and only occasionally moves to the epidermis (Soards et al. 2002), and this interferes with symptom expression. CMV $2 \mathrm{~b}$ is also responsible for enhancing tissue pervasiveness and modification of the tissue tropism of the DNA virus Abutilon mosaic virus during co-infections of $N$. benthamiana (Wege and Siegmund 2007). Moreover, the two TGMV proteins necessary for the mesophyll invasion, AL2 and BL1, act as silencing suppressors in $N$. benthamiana (Duan et al. 1997; Morra and Petty 2000; Voinnet et al. 1999). However, the mechanism determining the virus tissue tropism and the role of silencing suppression in this phenomenon still need to be fully elucidated.

\section{OuMV CP has some properties of a suppressor of plant defenses.}

The host-specific phenotypes observed for OuMV $\mathrm{V}_{6710}$ can be attributed to movement impairments, as well as to an impaired ability to escape (or actively suppress) antiviral defenses. RNA silencing is the major plant defense against viral infections. To efficiently infect their hosts, viruses have developed counterdefense strategies involving proteins that target and suppress the activity of the RNA-silencing pathway intra- or intercellularly (Baulcombe 2002; Burgyan and Havelda 2011; Pumplin and Voinnet 2013). The sequence and structure of these silencing suppression proteins are not conserved among virus taxa and, consequently, they are not identifiable by sequence homology. A common bioassay performed in 16C $N$. benthamiana plants is useful to show local silencing suppressor activity of viral proteins through ectopic expression (Baulcombe 2002).
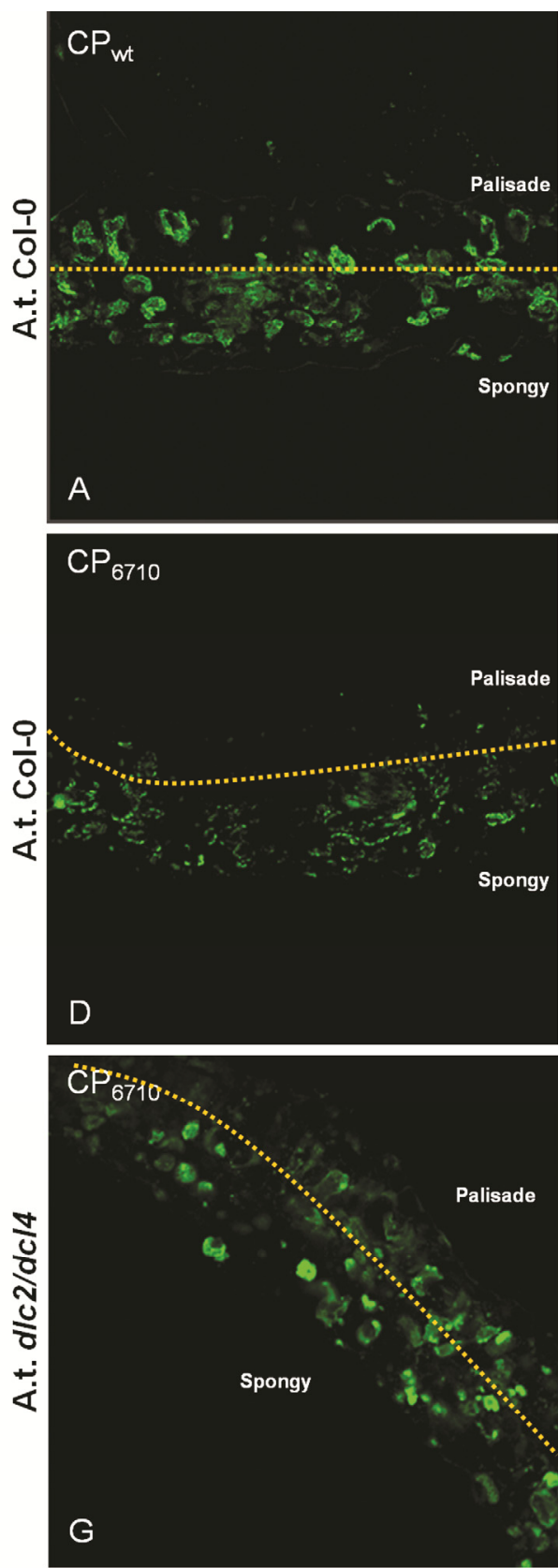
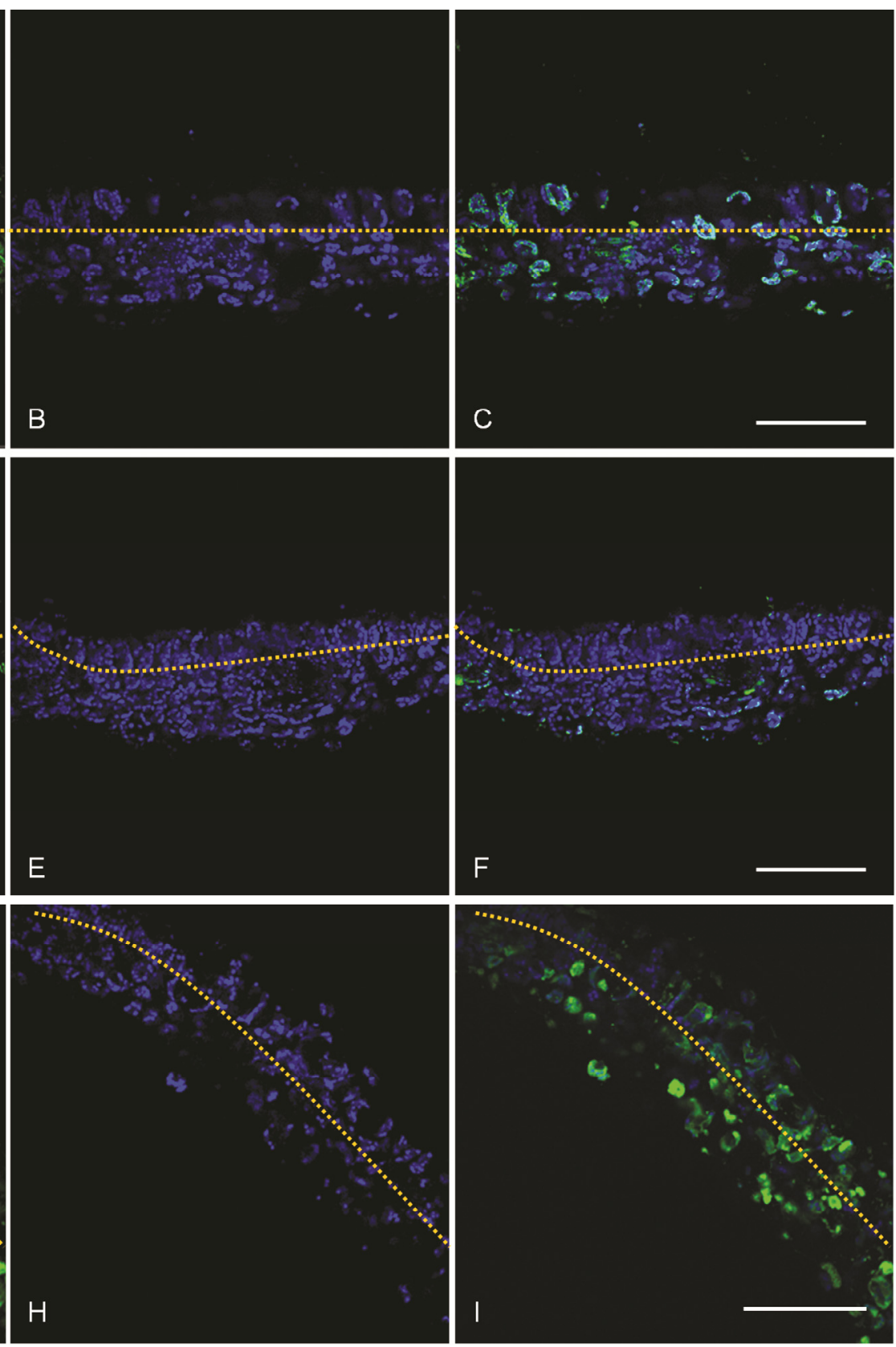

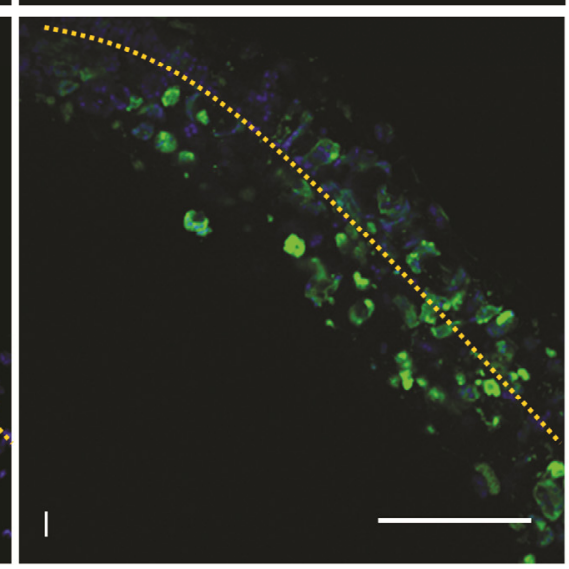

Fig. 10. Immunolocalization of OuMV coat protein $(\mathrm{CP})$ in transversal sections of Arabidopsis thaliana leaves infected with OuMV $\mathrm{wt}_{\mathrm{wt}}$ and OuMV 6710 . A, $\mathbf{D}$, and $\mathbf{G}$, Fluorescent signal of fluorescein isothiocyanate-conjugated, specific for viral CP accumulation; $\mathbf{B}, \mathbf{E}$, and $\mathbf{H}$, Fluorescent signal of chlorophyll (blue); $\mathbf{C}$, overlay of A and B; F, overlay of D and E; I, overlay of G and H. Dotted lines indicate the boundary between spongy and palisade tissue. Bars $=100 \mu \mathrm{m}$. 
This bioassay failed to reveal an OuMV protein with this function, including the CP. Nevertheless, OuMV CP has several functional analogies and common characteristics with other well-known silencing suppressors such as influences on virulence, tissue tropism, and effects on virus titer in infected tissues (Cao et al. 2010; Diaz-Pendon and Ding 2008; Soards et al. 2002; Wege and Siegmund 2007). Moreover, the different behaviors of OuMV $\mathrm{wt}_{\mathrm{wt}}$ and OuMV $\mathrm{V}_{6710}$ in relation to plant recovery from infection suggest that the mutant is more susceptible to silencing activities. The necrotic lesions initially observed and maintained 35 dpi on OuMV 6710 -infected leaves may, in fact, be a plant defense response to initial subliminal infections, which could soon be cleared below detection levels by antiviral defense without losing the symptoms caused by the initial necrotic response. A possible reason to explain the failure of the $16 \mathrm{C} N$. benthamiana test is that the $\mathrm{CP}$ antidefense activity may depend on its tertiary and quaternary structures, which may differ widely when comparing ectopic expression to expression in the context of virus infection. In fact, as we have previously shown, OuMV CP is not able to self-assemble and form capsids in plant cells if expressed alone but requires active RNA3 replication to form virions in the context of viral infection (Crivelli et al. 2011). For this reason, we repeated our assays using RNA1 in mixed infections with RNA2 or RNA3 replicative forms. However, even in this case, we were unable to detect measurable effects on GFP expression in 16C-silenced $N$. benthamiana. Although these results seemed to exclude a role of $\mathrm{CP}, \mathrm{MP}$, or RdRp as general silencing suppressors, we were able to identify a role for the $\mathrm{CP}$ in contrasting specific antivirus defenses by use of alternative genetic approaches. In fact, in silencing-impaired Arabidopsis plants ( dcl2/dcl3/dcl4 and $d c l 2 / d c l 4$ mutant plants), we were able to determine that $\mathrm{OuMV}_{6710}$ is able to accumulate and to display strong symptoms that are not distinguishable from those of OuMV $\mathrm{wt}_{\mathrm{w}}$. In these plants, the mutant $\mathrm{OuMV}_{6710}$ was able to infect the whole-leaf tissues to result in an almost complete complementation of the phenotype shown in WT Col-0 A. thaliana in terms of virus titer, symptom severity, and number of infected plants. Furthermore, p19 from TBSV, a well-characterized silencing suppressor, could almost specifically complement the lower accumulation of OuMV $\mathrm{V}_{6710}$ but had no effect on OuMV $\mathrm{wt}_{\mathrm{wt}}$ (the lack of full complementation could be due to the transient nature of p19 expression during agroinfiltration). Overall, these experiments support the idea that, when antiviral defense is inactivated, OuMV 6710 is not impaired in any fundamental life cycle activities, including replication and spread, and cannot be distinguished from the WT virus. Interactions between $\mathrm{CP}$ and viral genomic RNA are necessary for encapsidation of the viral genetic material but, in some cases, such as Turnip crinkle virus (TCV) p38 CP, the RNA-binding motif is crucial for silencing-suppression activity (Cao et al. 2010). In particular, it has been shown that the N-terminal region of p38 binds double-stranded RNA molecules independently of their size, and that these binding activities also include viral siRNA duplexes (Merai et al. 2005). This property is linked with the inhibition of the silencing machinery either by siRNA sequestration or by interference with Dicer activities. In particular, it has been demonstrated that p38 competes with Arabidopsis DCL4 (Deleris et al. 2006), and that mutations within the N-terminal p38 region compromise silencing-suppression activity (Cao et al. 2010). We showed that the basic OuMV N-terminal $\mathrm{CP}$ region is also involved in RNA-encapsidation in vivo and that amino acid substitutions that partially neutralize positive charges within the domain reduce this property. Reduced encapsidation efficiency of viral genetic material leads to exposure of $\mathrm{OuMV}_{6710}$ genomic RNA to the silencing machinery. In this case, the silencing- suppression activity of the $\mathrm{CP}_{\mathrm{wt}}$ would be indirect and dependent on its ability to protect the viral genetic material. However, it is also possible that the $\mathrm{CP}_{6710}$ has a reduced affinity for siRNA molecules (as shown for TCV) and that this reduction negatively affects the ability of the mutant to compete with the plant silencing machinery, resulting in an impaired silencing suppression. If this was the case, OuMV CP might be considered to be a direct silencing suppressor that actively works against plant defenses. However, it is difficult to distinguish between a generalized RNA protection effect due to encapsidation and a true silencing-suppression activity that not necessarily involves the encapsidation steps. Nevertheless, in our opinion, the protection of encapsidated RNA is not directly linked to antiviral defenses involving the silencing pathway because such defenses are effective on actively replicating RNA, whereas encapsidation itself subtracts genomic plusstrand RNA from the pool of RNA available for replication and represents the end point in the viral cycle. Therefore, less efficient encapsidation would actually increase the RNA molecules available for further replication rounds. Taking this into consideration, it is likely that the suppression of antiviral defense in OuMV does not depend on encapsidation efficiency but, instead, relies on other specific protein-RNA interactions, as shown for TCV (Merai et al. 2005). Furthermore, the fact that a lower encapsidation efficiency of genomic RNA is complemented functionally in Dicer mutants supports the action of the $\mathrm{CP}$ as a silencing suppressor that acts independently of encapsidation.

In addition to the unique evolutionary route that has led to their emergence, little is known about ourmiaviruses. In this work, we have extended our knowledge of OuMV CP and provided evidence for the key role played by the N-terminal KR region in its functional activities. All the OuMV CP functions highlighted in our work are clearly interwoven and seem to point to a common feature: interference with plant antiviral defenses. However, the mechanisms connecting silencing suppression and the phenomena involving tissue tropism, host range, pathogenicity, and RNA affinity need additional clarification. The ability of OuMV to infect a wide range of dicotyledonous plants (Rastgou et al 2009) and, in particular, Nicotiana spp. and Arabidopsis, may provide different avenues for basic and applied research on this phenomenon.

\section{MATERIALS AND METHODS}

\section{Agroinfectious clones and plant material.}

OuMV agroinfectious clones used in this study have been previously described (Crivelli et al. 2011). For this study, pGC-RNA3 (Crivelli et al. 2011) was used as template for the site-direct mutagenesis by PCR, as described by Rossi and associates (2014). Primers used are detailed in Table 3. To check the stability of the mutations during viral infection, RNA was extracted from the infected plants and cDNA from RNA3 was sequenced.

Solanaceae and Cucurbitaceae plants were grown in $10-\mathrm{cm}$ pots in a greenhouse at $25^{\circ} \mathrm{C}$ under a 14-h light regime. All Arabidopsis lines were grown in a greenhouse at $23^{\circ} \mathrm{C}$ with a 16-h light regime. Cucurbitaceae plants were mechanically inoculated 1 week after sowing whereas Solanaceae plants and Arabidopsis were inoculated 4 weeks after sowing.

A. thaliana mutant lines used in this study were purchased from the Nottingham Arabidopsis Stock Centre germplasm: $d c l 1, d c l 2 / d c l 3, d c l 2 / d c l 4$, and $d c l 2 / d c l 3 / d c l 4$ (Bouché et al. 2006; Deleris et al. 2006; Gasciolli et al. 2005 Jacobsen et al. 1999; Xie et al. 2005). All of them were in Col-0 background. The $N$. benthamiana 16C transgenic line was previously described (Ruiz et al. 1998; Voinnet et al. 1998). 
Agroinfection and mechanical inoculation.

Mechanical inoculations were performed using $0.05 \mathrm{M}$ phosphate buffer, with Carborundum powder previously dusted on leaves as an abrasive.

For $N$. benthamiana agroinfection, each plasmid was transformed into Agrobacterium tumefaciens C58C1 and agroinfiltrated in young leaves, as previously described (Bendahmane et al. 1999, 2002; Margaria et al. 2007). To standardize the experiments, the absorbance (optical density at $600 \mathrm{~nm}$ ) of the Agrobacterium cultures was measured and each agroclone was adjusted to a final concentration corresponding to an absorbance of 0.25 .

\section{DAS-ELISA and Western blot analysis of leaf extracts.}

Crude extracts from $0.5 \mathrm{~cm}$ diameter disc of plant leaf tissue were obtained by mechanical homogenization in $1 \mathrm{ml}$ of phosphate-buffered saline (PBS)-Tween buffer containing 2\% (wt/vol) polyvinyl pyrrolidone (PVP). For DAS-ELISA, specific anti-CP polyclonal serum (purified immunoglobulin $G$ [IgG] at $2 \mathrm{mg} / \mathrm{ml}$ from antiserum A255 from the Istituto di Virologia Vegetale [IVV] collection) was used to coat Greiner high-binding plates. The alkaline phosphatase conjugate anti$\mathrm{CP}$ antibody was used diluted 1/1,000 in PBS-Tween buffer. A preliminary assay with serial dilution of the plant extract was carried out in order to find the concentration ranges where ABS was linear to virus titer: therefore, plant extracts were further diluted 1/5 in PBS-Tween buffer. In each ELISA plate, a standard dilution curve from $N$. benthamiana infected with $\mathrm{OuMV}_{\mathrm{wt}}$ was inserted for relative quantification of each sample.

Sodium dodecyl sulfate polyacrylamide gel electrophoresis of total leaf extracts and subsequent Western blot were carried out as previously described (Rastgou et al. 2009). Anti-CP antibodies (purified IgG from antiserum A255 from the IVV collection) were diluted 1:2,000 in blocking buffer. Secondary horseradish peroxidase antibodies (Sigma-Aldrich) were used at the final dilution of 1:2,500.

\section{Viral particle purification}

\section{and whole virus particles agarose gel analysis.}

Viral particles were partially purified from systemically infected leaves of $N$. benthamiana 7 days postagroinfection. Protocols for partial purification and agarose separation of whole virus particles described by Crivelli and associates (2011) were used, with some modification. Briefly $1 \mathrm{~g}$ of agroinfiltrated leaves was homogenized in $8 \mathrm{ml}$ of protein extraction buffer (Navarro et al. 2004) and incubated at $37^{\circ} \mathrm{C}$ for $30 \mathrm{~min}$. The extract was then mixed with an equal volume of chloroform and centrifuged at $3,000 \times g$ for $10 \mathrm{~min}$. The supernatant was treated with $10 \%$ polyethylene glycol (PEG) 8,000 and $1 \% \mathrm{NaCl}$ and precipitated for $30 \mathrm{~min}$ at $4{ }^{\circ} \mathrm{C}$. After centrifugation at $4,000 \times g$ for $20 \mathrm{~min}$, the pellet was resuspended in 300 $\mathrm{ml}$ of $0.05 \mathrm{M}$ phosphate buffer ( $\mathrm{pH} 7)$. Whole-virus separation was performed on agarose gel prepared and run as previously described (Qiu and Scholthof 2001) and transferred either to nitrocellulose or nylon membrane following protocols described by Qi and associates (2008). Nylon membranes were subjected to Northern analysis and hybridized with an RNA3 probe, as previously described for Northern blots (Crivelli et al. 2011), whereas the nitrocellulose membrane was subjected to Western analysis and exposed to specific anti-CP polyclonal antibodies (purified IgG from antiserum A255 from IVV collection), as previously described (Crivelli et al. 2011). The intensity of hybridization bands was measured with ImageJ software.

\section{Leaf sections, immunolocalization and confocal microscopy.}

Leaves were cut in small pieces and then fixed overnight at $4^{\circ} \mathrm{C}$ in $4 \%$ paraformaldehyde in PBS ( $\mathrm{pH} 7.4$ ). After washing with PBS, they were embedded in $8 \%$ (wt/vol) low-melting agarose. Transversal sections, $100 \mu \mathrm{m}$ thick, were obtained with a vibrating blade microtome (Leica VT1000S). Sections were blocked at room temperature for $30 \mathrm{~min}$ with $1 \%$ bovine serum albumen (BSA) in PBS and incubated overnight at $4{ }^{\circ} \mathrm{C}$ with the polyclonal anti-CP primary antibody (A253VI from the IVV collection). The sections were then washed three times with PBS, blocked at room temperature for $30 \mathrm{~min}$ with $1 \%$ BSA in PBS, then incubated for $2 \mathrm{~h}$ with fluorescein isothiocyanate-conjugated (FITC) goat antirabbit IgG antibody (Sigma-Aldrich). After washing with PBS, a few drops of a 1$\mathrm{mg} / \mathrm{ml}$ solution of 4',6-diamidino-2-phenylindole (DAPI) were used to stain plant nuclei. Sections treated without primary antibody or secondary antibody served as negative controls (not shown). Sections were examined in confocal laser-scanning microscopy using a Leica TCS-SP2 microscope (Leica Microsystems, Mannheim, Germany) equipped with a longdistance 40x water immersion objective (HCX Apo 0.80). A 488-nm Argon laser line was used to excite FITC, which was imaged using an emission window of 500 to 525. A near-UV diode $(405 \mathrm{~nm})$ was used to excite DAPI and the emitted fluorescence was collected between 410 and $490 \mathrm{~nm}$. Chloroplasts were imaged, taking advantage of chlorophyll auto-fluorescence at 650 to $700 \mathrm{~nm}$ (excited at $488 \mathrm{~nm}$ ). Laser intensity and detector gain were first set on uninfected samples and then the same settings were kept for all the subsequent observations.

\section{EM.}

Infected leaves were crushed and homogenized in $0.1 \mathrm{M}$ phosphate buffer, $\mathrm{pH} 7.0$, containing $2 \%$ PVP. A drop of the crude extract was allowed to adsorb for 3 min on carbon and formvar-coated grids and then rinsed several times with water. For immunosorbent EM, grids were first incubated for $5 \mathrm{~min}$ with a dilution of the polyclonal anti-CP primary antibody (A253VI from the IVV collection) and rinsed several times with $0.1 \mathrm{M}$ phosphate buffer, $\mathrm{pH}$ 6.8. A drop of the crude extract was then applied on the grid, incubated for $15 \mathrm{~min}$, and rinsed several times with water. Grids were negatively stained with $0.5 \%$ uranyl acetate and excess fluid was removed with filter paper (Milne 1993). Observations and photographs were made using a CM10 electron microscope (Philips, Eindhoven, The Netherlands). For virus particle quantification, $30 \mu \mathrm{l}$ of the homogenizing buffer was added for each milligram of fresh leaf weight. Dilution series of the leaf extract were then prepared in order to stay below the saturation level and find a

Table 3. Oligonucleotides used for polymerase chain reaction and site directed mutagenesis

\begin{tabular}{lll}
\hline Construct name & \multicolumn{1}{c}{ Forward primer $\left(\mathbf{5}^{\prime} \mathbf{-} \mathbf{3}^{\prime}\right)$} & \multicolumn{1}{c}{ Reverse primer $\left(\mathbf{5}^{\prime} \mathbf{- \mathbf { 3 } ^ { \prime } )}\right.$} \\
\hline pGC-CP- $\Delta(5-11)$ & AATGAGAAGAAGAAGAACGCACG & GAGTCTGGCCATGGTGATCCGTTCG \\
pGC-CP- $\Delta(5-13)$ & AAGAAGAAGAACGCAAACGCATCGAGG & GAGTCTGGCCATGGTGATCCGTTCG \\
pGC-CP- $\Delta(5-16)$ & AACGCAAACGCATCGAGGGTCCAAAATG & GAGTCTGGCCATGGTGATCCGTTCG \\
pGC-CP-10 R/A & CTCCCAAAGAGAAAGAATGCACGTAATGAGAAGAA & TTCTTCTCATTACGTGCATTCTTTCTCTTTGGGAG \\
pGC-CP-6,7-KR/AA & CCAGCGGCAAAGAATCGACGTAATG & GAGTCTGGCCATGGGCTTGTACAGC \\
pGC-CP-6,7,10-KRR/AAA & CTCCCAAAGAGAAAGAATGCACGTAATGAGAAGAA & TTCTTCTCATTACGTGCATTCTTTCTCTTTGGGAG \\
\hline
\end{tabular}

a On pGC-CP-6,7-KR/AA as template. 
range where particle counts were correlated with dilution factor. Particles were counted manually on at least 10 meshes for each microscope grid.

\section{Low molecular weight RNAs isolation and Northern blot analysis.}

Arabidopsis plants were mechanically infected with standardized concentrations of $\mathrm{OuMV}_{\mathrm{wt}}$ and $\mathrm{OuMV}_{6710}$. At $10 \mathrm{dpi}, 3 \mathrm{~g}$ of virus-infected plant material was harvested, frozen in liquid nitrogen, and ground to a fine powder. Total RNA was extracted with TRIZOL reagent and dissolved in diethylpyrocarbonate (DEPC) water to $1 \mu \mathrm{g} / \mu \mathrm{l}$ final concentration. High molecular weight (HMW) RNAs (mRNAs and rRNAs) were precipitated by adding PEG8000 to a final concentration of 5\% and $\mathrm{NaCl}(0.5 \mathrm{M}$ final). After centrifugation, the supernatant (low molecular weight [LMW] RNA) was removed and transferred to a new tube. The pellet (HMW RNAs) was washed with $75 \% \mathrm{EtOH}$ and dissolved in DEPC water. To recover the LMW RNAs, the supernatant was mixed with 3 vol of $100 \%$ $\mathrm{EtOH}$ and placed at $-20^{\circ} \mathrm{C}$ for $2 \mathrm{~h}$. After centrifugation $\left(13,000 \mathrm{rpm}, 30 \mathrm{~min}\right.$ at $\left.4^{\circ} \mathrm{C}\right)$, supernatant was discarded and the pellet was washed with $75 \% \mathrm{EtOH}$ and dissolved in DEPC water.

LMW RNA ( $5 \mu \mathrm{g}$ ) was separated on denaturing $8 \mathrm{M}$ urea $15 \%$ polyacrylamide gel. MicroRNA marker (New England Biolabs) was used on the same gel to estimate RNA sizes. LMW RNAs were transferred to a positively charged nylon membrane (Merck Millipore). Probe synthesis, hybridization, and washes were carried out as previously detailed (Rosa et al. 2010). Northern blot analysis of HMW RNA was performed as detailed by Rastgou and associates (2009).

The intensity of hybridization bands was measured with ImageJ software.

\section{ACKNOWLEDGMENTS}

M. Rossi was supported by a scholarship from Regione Piemonte. We thank C. Perrone and R. Lenzi for technical assistance; and A. Jackson, Professor Emeritus, University of California-Berkeley, for editing the manuscript and for helpful discussion on further development of this research.

\section{LITERATURE CITED}

Baulcombe, D. C. 2002. Viral suppression of systemic silencing. Trends Microbiol. 10:306-308.

Bendahmane, A., Kanyuka, K., and Baulcombe, D. C. 1999. The Rx gene from potato controls separate virus resistance and cell death responses. Plant Cell 11 5:781-791.

Bendahmane, A., Farnham, G., Moffett, P., and Baulcombe, D. C. 2002. Constitutive gain-of-function mutants in a nucleotide binding site-leucine rich repeat protein encoded at the Rx locus of potato. Plant $\mathrm{J}$. 32:195-204.

Bouché, N., Lauressergues, D., Gasciolli, V., and Vaucheret, H. 2006. An antagonistic function for Arabidopsis DCL2 in development and a new function for DCL4 in generating viral siRNAs. EMBO (Eur. Mol. Biol. Organ.) J. 25:3347-3356.

Burgyan, J., and Havelda Z. 2011. Viral suppressors of RNA silencing. Trends Plant Sci. 16:265-272.

Callaway, A., Giesman-Cookmeyer, D., Gillock, E. T., Sit, T. L., and Lommel, S. A. 2001. The multifunctional capsid proteins of plant RNA viruses. Annu. Rev. Phytopathol. 39:419-460.

Cao, M., Ye, X., Willie, K., Lin, J., Zhang, X., Redinbaugh, M. G., Simon, A. E., Morris, T. J., and Qu, F. 2010. The capsid protein of Turnip crinkle virus overcomes two separate defense barriers to facilitate systemic movement of the virus in Arabidopsis. J. Virol. 84:7793-7802.

Carbonell, A., Maliogka, V. I., de Jesus Perez, J., Salvador, B., San Leon, D., Antonio Garcia, J., and Simon-Mateo, C. 2013. Diverse amino acid changes at specific positions in the $\mathrm{N}$-terminal region of the coat protein allow Plum pox virus to adapt to new hosts. Mol. Plant-Microbe Interact. 26:1211-1224.

Crivelli, G., Ciuffo, M., Genre, A., Masenga, V., and Turina, M. 2011. Re- verse genetic analysis of Ourmiaviruses reveals the nucleolar localization of the coat protein in Nicotiana benthamiana and unusual requirements for virion formation. J. Virol. 85:5091-5104.

Deleris, A., Gallego-Bartolome, J., Bao, J., Kasschau, K. D., Carrington, J. C., and Voinnet, O. 2006. Hierarchical action and inhibition of plant Dicer-like proteins in antiviral defense. Science 313:68-71.

Diaz-Pendon, J. A., and Ding, S. W. 2008. Direct and indirect roles of viral suppressors of RNA silencing in pathogenesis. Annu. Rev. Phytopathol. 46:303-326.

Dolja, V. V., and Koonin, E. V. 1991. Phylogeny of capsid proteins of small icosahedral rna plant-viruses. J. Gen. Virol. 72:1481-1486.

Dolja, V. V., Haldeman, R., Robertson, N. L., Dougherty, W. G., and Carrington, J. C. 1994. Distinct functions of capsid protein in assembly and movement of tobacco etch potyvirus in plants. EMBO (Eur. Mol. Biol. Organ.) J. 13:1482-1491.

Dolja, V. V., Haldeman-Cahill, R., Montgomery, A. E., Vandenbosch, K. A., and Carrington, J. C. 1995. Capsid protein determinants involved in cell-to-cell and long distance movement of tobacco etch potyvirus. Virology 206:1007-1016.

Duan, Y. P., Powell, C. A., Webb, S. E., Purcifull, D. E., and Hiebert, E 1997. Geminivirus resistance in transgenic tobacco expressing mutated BC1 protein. Mol. Plant-Microbe Interact 10:617-623.

Gasciolli, V., Mallory, A. C., Bartel, D. P, and Vaucheret, H. 2005. Partially redundant functions of Arabidopsis DICER-like enzymes and a role for DCL4 in producing trans-acting siRNAs. Curr. Biol. 15:1494-1500.

Guerra-Peraza, O., Kirk, D., Seltzer, V., Veluthambi, K., Schmit, A. C., Hohn, T., and Herzog, E. 2005. Coat proteins of Rice tungro bacilliform virus and Mungbean yellow mosaic virus contain multiple nuclear-localization signals and interact with importin alpha. J. Gen. Virol. 86:1815-1826.

Herranz, M. C., Pallas, V., and Aparicio, F. 2012. Multifunctional roles for the N-terminal basic motif of Alfalfa mosaic virus coat protein: Nucleolar/cytoplasmic shuttling, modulation of RNA-binding activity, and virion formation. Mol. Plant-Microbe Interact. 25:1093-1103.

Hsu, C., Singh, P., Ochoa, W., Manayani, D. J., Manchester, M. Schneemann, A., and Reddy, V. S. 2006. Characterization of polymorphism displayed by the coat protein mutants of Tomato bushy stunt virus. Virology 349:222-229.

Hu, C. C., and Ghabrial, S. A. 1995. The conserved, hydrophilic and arginine-rich $\mathrm{N}$-terminal domain of cucumovirus coat proteins contributes to their anomalous electrophoretic mobilities in sodium dodecyl-sulfate-polyacrylamide gels. J. Virol. Methods 55:367-379.

Jacobsen, S. E., Running, M. P., and Meyerowitz, E. M. 1999. Disruption of an RNA helicase/RNAse III gene in Arabidopsis causes unregulated cell division in floral meristems. Development 126:5231-5243.

Jovel, J., Walker, M., and Sanfacon, H. 2007. Recovery of Nicotiana benthamiana plants from a necrotic response induced by a nepovirus is associated with RNA silencing but not with reduced virus titer. J. Virol. 81:12285-12297.

Kaplan, I. B., Zhang, L., and Palukaitis, P. 1998. Characterization of Cucumber mosaic virus V. Cell-to-cell movement requires capsid protein but not virions. Virology 246:221-231.

King, A. M. Q., Lefkowitz E., Adams, M. J., and Carstens, E. B. 2012. Virus Taxonomy: Ninth Report of the International Committee on Taxonomy of Viruses. Elsevier Academic Press, San Diego, CA, U.S.A.

Lee, S. K., and Hacker, D. L. 2001. In vitro analysis of an RNA binding site within the N-terminal 30 amino acids of the Southern cowpea mosaic virus coat protein. Virology 286:317-327.

Lisa, V., Milne, R. G., Boccardo, G., Caciagli, P., and Parvizy R. 1988. Ourmia melon virus, a virus from Iran with novel properties. Ann. Appl. Biol. 112:291-302.

Margaria, P., Ciuffo, M., Pacifico, D., and Turina, M. 2007. Evidence that the nonstructural protein of Tomato spotted wilt virus is the avirulence determinant in the interaction with resistant pepper carrying the Tsw gene. Mol. Plant-Microbe Interact. 20:547-558.

Merai, Z., Kerenyi, Z., Molnar, A., Barta, E., Valoczi, A., Bisztray, G., Havelda, Z., Burgyan, J., and Silhavy, D. 2005. Aureusvirus P14 is an efficient RNA silencing suppressor that binds double-stranded RNAs without size specificity. J. Virol. 79:7217-7226.

Milne, R. G. 1993. Solid-phase immune electron microscopy of virus preparations. Pages 25-70 in: Immuno-Gold Electron Microscopy in Virus Diagnosis and Research. A. D. Hyatt and B. Eaton, eds. CRC Press, Boca Raton, FL, U.S.A.

Morra, M. R., and Petty, I. T. D. 2000. Tissue specificity of geminivirus infection is genetically determined. Plant Cell 12:2259-2270.

Navarro, B., Rubino, L., and Russo M. 2004. Expression of the Cymbidium ringspot virus 33-kilodalton protein in Saccharomyces cerevisiae and molecular dissection of the peroxisomal targeting signal. J. Virol. 78:4744-4752.

Ni, P., Wang, Z., Ma, X., Das, N. C., Sokol, P., Chiu, W., Dragnea, B., 
Hagan, M., and Kao, C. C. 2012. An examination of the electrostatic interactions between the $\mathrm{N}$-terminal tail of the brome mosaic virus coat protein and encapsidated RNAs. J. Mol. Biol. 419:284-300.

Olspert, A., Paves, H., Toomela, R., Tamm T., and Truve, E. 2010. Cocksfoot mottle sobemovirus coat protein contains two nuclear localization signals. Virus Genes 40:423-431.

Palani, P. V., Kasiviswanathan, V., Chen, J. C. F., Chen, W., Hsu, Y. H., and Lin, N. S. 2006. The arginine-rich motif of Bamboo mosaic virus satellite RNA-encoded P20 mediates self-interaction, intracellular targeting, and cell-to-cell movement. Mol. Plant-Microbe Interact. 19:758-767.

Pumplin, N., and Voinnet O. 2013. RNA silencing suppression by plant pathogens: Defence, counter-defence and counter-counter-defence. Nat. Rev. Microbiol. 11:745-760.

Qi, D., Omarov, R. T., and Scholthof, K. B. G. 2008. The complex subcellular distribution of satellite Panicum mosaic virus capsid protein reflects its multifunctional role during infection. Virology 376:154-164.

Qiu, W. P., and Scholthof, K.-B. G. 2001. Genetic identification of multiple biological roles associated with the capsid protein of satellite panicum mosaic virus. Mol. Plant-Microbe Interact. 14:21-31.

Rao, A. L. N., and Grantham, G. L. 1995. Biological significance of the 7 amino-terminal basic residues of brome mosaic-virus coat protein. Virology 211:42-52.

Rao, A. L. N., and Grantham, G. L. 1996. Molecular studies on Bromovirus capsid protein 2. Functional analysis of the amino-terminal arginine-rich motif and its role in encapsidation, movement, and pathology. Virology 226:294-305.

Rastgou, M., Habibi, M. K., Izadpanah, K., Masenga, V., Milne, R. G., Wolf, Y. I., Koonin, E. V., and Turina, M. 2009. Molecular characterization of the plant virus genus Ourmiavirus and evidence of inter-kingdom reassortment of viral genome segments as its possible route of origin. J. Gen. Virol. 90:2525-2535.

Reade, R., Kakani, K., and Rochon, D. A. 2010. A highly basic KGKKGK sequence in the RNA-binding domain of the Cucumber necrosis virus coat protein is associated with encapsidation of full-length CNV RNA during infection. Virology 403:181-188.

Rosa, C., Kamita, S. G., Dequine, H., Wuriyanghan, H., Lindbo, J. A., and Falk, B. W. 2010. RNAi effects on actin mRNAs in Homalodisca vit ripennis cells. J. RNAi Gene Silencing 6:361-366.

Rossi, M., Genre, A., and Turina, M. 2014. Genetic dissection of a putative nucleolar localization signal in the coat protein of Ourmia melon virus. Arch. Virol. 159:1187-1192.

Rossmann, M. G., and Johnson, J. E. 1989. Icosahedral RNA virus structure. Annu. Rev. Biochem. 58:533-573.
Ruiz, M. T., Voinnet, O., and Baulcombe, D. C. 1998. Initiation and maintenance of virus-induced gene silencing. Plant Cell 10:937-946.

Ruiz-Ruiz, S., Soler, N., Sanchez-Navarro, J., Fagoaga, C., Lopez, C., Navarro, L., Moreno, P., Pena, L., and Flores, R. 2013. Citrus tristeza virus p23: Determinants for nucleolar localization and their influence on suppression of RNA silencing and pathogenesis. Mol. Plant-Microbe Interact. 26:306-318.

Schmitz, I., and Rao, A. L. N. 1998. Deletions in the conserved amino-terminal basic arm of cucumber mosaic virus coat protein disrupt virion assembly but do not abolish infectivity and cell-to-cell movement. Virology 248:323-331.

Scholthof, H. B. 2005. Plant virus transport: Motions of functional equivalence. Trends Plant Sci. 10:376-382.

Sharma, P., and Ikegami, M. 2009. Characterization of signals that dictate nuclear/nucleolar and cytoplasmic shuttling of the capsid protein of Tomato leaf curl java virus associated with DNA beta satellite. Virus Res. 144:145-153.

Sit, T. L., Haikal, P. R., Callaway, A. S., and Lommel, S. A. 2001. A single amino acid mutation in the Carnation ringspot virus capsid protein allows virion formation but prevents systemic infection. J. Virol. 75:9538-9542.

Soards, A. J., Murphy, A. M., Palukaitis, P., and Carr, J. P. 2002. Virulence and differential local and systemic spread of Cucumber mosaic virus in tobacco are affected by the CMV 2b protein. Mol. Plant-Microbe Interact. 15:647-653.

Voinnet, O., Vain, P., Angell, S., and Baulcombe, D. C. 1998. Systemic spread of sequence-specific transgene RNA degradation in plants is initiated by localized introduction of ectopic promoterless DNA. Cell 95:177-187.

Voinnet, O., Pinto, Y. M., and Baulcombe, D. C. 1999. Suppression of gene silencing: A general strategy used by diverse DNA and RNA viruses of plants. Proc. Nat. Acad. Sci. U.S.A. 96:14147-14152.

Wege, C., and Siegmund, D. 2007. Synergism of a DNA and an RNA virus: Enhanced tissue infiltration of the begomovirus Abutilon mosaic virus (AbMV) mediated by Cucumber mosaic virus (CMV). Virology 357:10-28.

Xie, Z. X., Allen, E., Wilken, A., and Carrington, J. C. 2005. DICERLIKE 4 functions in trans-acting small interfering RNA biogenesis and vegetative phase change in Arabidopsis thaliana. Proc. Nat. Acad. Sci. U.S.A. 102:12984-12989.

Yusibov, V. M., and Loeschfries, L. S. 1995. N-terminal basic-amino-acids of alfalfa mosaic-virus coat protein involved in the initiation of infection. Virology 208:405-407. 